\title{
PROCESSO SUCESSÓRIO EM EMPRESAS FAMILIARES: UMA LEITURA COMUNICACIONAL, A PARTIR DO PENSAMENTO SISTÊMICO ${ }^{1}$
}

\author{
FAMILY BUSINESSES SUCCESSION PROCESS: A COMMUNICATIONAL \\ READING ACCORDING TO SYSTEM THINKING
}

\author{
Ivone Maria Correia de Almeida Pires do Rosário², Robson Dias³, \\ Victor Márcio Laus Reis Gomes ${ }^{4}$ e João José de Avevedo Curvello ${ }^{5}$
}

\section{RESUMO}

O artigo teórico, exploratório, qualitativo, interpreta o processo sucessório em empresa familiar a partir do arcabouço teórico do Pensamento Sistêmico, em Niklas Luhmann, que tem como viés a construção da realidade com base na interação e na comunicação. O processo sucessório familiar é um tema de ampla investigação na Administração, mas em Comunicação ainda é pouco estudado. A empresa familiar possui contratos reificados na Cultura Organizacional que são colocados em cheque em processos de troca de lideranças, fusões, transição de forma jurídica (responsabilidade limitada, sociedade anônimas, capital aberto) e profissionalização da gestão. O planejamento para a sucessão de gerações costuma ter desafios a serem enfrentados por empresas familiares locais, regionais, nacionais e multinacionais. No artigo, analisamos o fenômeno a partir de variáveis como nepotismo, paternalismo, protecionismo, comodismo, relacionamento com públicos, circulação de informação organizacional, presença (ou não) de planejamento, identificadas em Rosário (2016). Utilizamos a baliza da Comunicação Organizacional como fenômeno, como processo e como sistema (CURVELLO, 2009). O objetivo é o de ofertar uma interpretação da comunicação e das organizações como sistemas complexos: uma leitura comunicacional da estratégia (GOMES, 2014) nesses processos sucessórios.

Palavras-Chave: Comunicação Organizacional, Processo Sucessório Familiar. Comunicação Estratégica.

\section{ABSTRACT}

The theoretical, exploratory, qualitative article interprets the succession process in a family business from the theoretical framework of Systemic Thinking, in Niklas Luhmann, whose bias is the construction of reality

1 Este artigo está vinculado à linha de Processos Comunicacionais nas Organizações, e ao Grupo de Estudos Avança- dos de Comunicação Mediática e Organizacional, do Programa de Pós-Graduação em Comunicação (PPGCOM/UCB), da Universidade Católica de Brasília (UCB). E é base da pesquisa: Processo sucessório em empresas familiares: uma leitura a partir da comunicação organizacional e suas dimensões. E tem relação com 3 grupos de pesquisa da UCB e da Universidade de Brasília (UnB): Grupo de Pesquisa em Comunicação Organizacional e Pensamento Sistêmico (COMSiS)(1), - Núcleo de Estudos Comunicacionais da Estratégia (ESTRACOM)(2) e - Grupo de Pesquisa Prêmios, Indicadores e Estratégias em Comunicação (3). 2 Mestre em Comunicação pela Universidade Católica de Brasília (2016); especialista em Marketing (2005) e em Docência Superior pelo ICESP (2005); graduada em Direito pela Universidade Gama Filho (1996); publicitária pela Universidade Gama Filho (1988). Coordenadora acadêmica da Faculdade CECAP. E-mail: ivone.rosario@ucb.br

3 Jornalista, mestre e doutor em Comunicação. Professor e pesquisador do mestrado em Comunicação da Universidade Católica de Brasília (PPGSSCOM/UCB), linha Processos Comunicacionais nas Organizações. E-mail: robson.dias@ucb.br 4 Publicitário, mestre em Administração e doutor em Comunicação. Professor e pesquisador do PPGSSCOM/UCB, linha Processos Comunicacionais nas Organizações. Líder do grupo de pesquisa: Núcleo de Estudos Comunicacionais da Estratégia (ESTCOM). E-mail: victor.gomes@ucb.br

5 Jornalista, mestre e doutor em Comunicação. Professor ecoordenador do curso de Comunicação Organizacional (UnB) e pesquisador da linha de Teorias e Tecnologias de Comunicação (PPGFAC/UnB). Líder do grupo de Pesquisa em Comunicação Organizacional e Pensamento Sistêmico (COMSiS). E-mail: curvello@unb.br 
based on interaction and communication. The family succession process is a subject of ample investigation in the Administration, but in Communication: it is still little studied. The family company has reified contracts in the Organizational Culture that are placed in check in processes of leadership change, mergers, legal transition (limited liability, joint stock company, open capital) and professional management. Generational succession planning often has challenges for local, regional, national, and multinational family businesses. In the article, we analyse the phenomena from variables such as nepotism, paternalism, protectionism, comfort, relationship with publics, circulation of organizational information, presence (or not) of planning. We use the Beacon of Organizational Communication as a phenomenon, as a process and as a system (CURVELLO, 2009). The objective is to offer an interpretation of communication and of organizations as complex systems: a communicational reading (GOMES, 2014) of these succession processes.

Keywords: Organizational Communication. Family Succession Process. Strategic Communication.

\section{INTRODUÇÃO}

A Teoria dos Sistemas Sociais, em Niklas Luhmann (2011), confronta a perspectiva estrutural-funcionalista de Talcott Parsons e é uma opção à perspectiva da Teoria Geral dos Sistemas do biólogo Ludwig Von Bertalanffy ${ }^{6}$. A principal diferença dessas teorizações está no fato de que sistemas são operacionalmente fechados, para Luhmann, ou abertos, para Bertalanffy. Outra característica da Teoria dos Sistemas Sociais é a centralidade da Comunicação nos processos. Para Luhmann (2011, p. 7): “comunicar não é se desfazer de nada, é, antes de tudo, um processo multiplicador." O que é uma noção muito importante para a Comunicação Organizacional, por entender que a produção de sentido é que constrói a realidade. Assim, como veremos à frente: o processo sucessório em empresa familiar é uma forma de estratégia, ou seja, de planejamento da passagem de liderança do predecessor para o sucessor, na qual muitas dimensões desse processo acontecem na esfera da Cultura Organizacional (MARCHIORI, 2006) o que pode dar legitimidade (ou não) ao dirigente. A abordagem sistêmica tem a consciência e os sentidos atribuídos a ela e compartilhados como a noção de realidade, para muito além da estratificação social e da linguagem (estruturalismo) ou mesmo dos papéis sociais mantenedores das relações (funcionalismo). No pensamento sistêmico, a comunicação tem papel central por dar o denominador comum de sentido. E, logo, da realidade. Isso reifica o fenômeno em apreço no conflito entre família e negócio, no ciclo de vida geracional (Conselho de Família, Assembleia de Família) no Conselho de Administração da empresa, além dos limites de poder relativos ao espólio dos acionistas (herdeiros) e da empresa em si (sucessores), resiliência a erros cometidos por membros familiares, hierarquia paralela a dos cargos com a sinalização do poder do clã familiar (antimeritocracia), centralização das decisões, estranhamento entre divisão de trabalho e hierarquia familiar (herdeiros em posições funcionais menores que profissionais não-familiares), tensão entre tradição e conservadorismo e valores inovadores e competitivos. Todos esses aspectos têm

6 Os sistemas são definidos por Bertalanffy (1977) como um conjunto de elementos em interação. Os sistemas biológicos, neurológicos, psicológicos e sociais “são governados pela interação dinâmica de seus componentes” (BERTALANFFY, 1977, p. 70) 
efeito na Cultura Organizacional e sentidos são produzidos e compartilhados por cada indivíduo : na tomada de consciência e na tomada de decisão, o que incide na mentalidade e concepção de mundo, de família e de negócio da primeira, segunda, terceira geração familiar na empresa ${ }^{8}$.

O fenômeno base para a consciência é a cognição, um processo mental que pode levar ao aprendizado, reconhecimento, representação, percepção, dentre outros. Inúmeros saberes se voltam para a cognição que, para nós, no âmbito deste artigo, é definido como uma operação sistêmica que produz sentido e o organiza a realidade. Luhmann (2011, p. 7) sobre a centralidade da comunicação:

Assim, em todas as áreas programáticas dos meios de comunicação está implicado o "ser humano", mas, naturalmente, não como reprodução real de seus processos bioquímicos, imunológicos, neurológicos ou de consciência, mas apenas como construto social. O construto do "ser humano cognitivamente mais ou menos informado, apto a decisões, moralmente responsável", serve para que o sistema de função dos meios de comunicação irrite-se a si mesmo continuamente, considerando seu ambiente humano biológico e psíquico. Assim como em outros sistemas de função, também esse meio externo permanece operativamente inalcançável, ele não pode ser acoplado peça por peça e precisa, por isso, continuamente ser "lido". (LUHMANN, 2011, p.7).

A respeito da comunicação, comentadores brasileiros de Luhmann enfatizam que

A comunicação surge como a esperança de encontrar para o social um equivalente à operação bioquímica que aconteceu com as proteínas. Ou seja, a esperança de identificar o tipo de operador que torna possível todos os sistemas de comunicação, por mais complexo que tenham se tornado no curso da evolução: interações, organizações, sociedades. Tudo o que existe e que se pode designar como social consta, que se fundamenta na operação, de um mesmo impulso e um mesmo tipo de acontecimento: a comunicação. (RODRIGUES \& NEVES, 2012, p. 59).

Diante desta afirmação, a comunicação nas empresas é um elemento primordial ao bom andamento da rotina organizacional, seja nas relações entre as pessoas, nos processos de produção ou planejamento estratégico, por exemplo. Porém, é importante destacar o posicionamento de Gomes (2014, p. 57-58) a respeito da comunicação.

É possível dizer, portanto, que há dificuldades de comunicação entre discursos gerados em sistemas distintos. O mesmo ocorre entre diferentes organizações, que constituem sistemas independentes. Cada organização pode ser considerada um sistema autônomo, autorreferencial, que possui sua própria trajetória e segue sua própria lógica, com base na qual suas comunicações ou discursos são (re) produzidos. (GOMES, 2014, p. 57-58).

\footnotetext{
7 São elementos em comunicação na Cultura Organizacional: ambiente físico, artefatos inanimados de ornamentação, vestuário, corpo, linguagens, símbolos, gestos, códigos, histórias, narrativas, lendas, folclores, mitos, ritos, crenças, heróis, personagens, cerimônias, protocolos, rituais, além de ações dos indivíduos que influenciem a cultura (confidentes, espiões, fofoqueiros, líderes e conspiradores), fluxos extra-organizacionais (rádio corredor, happy hour, whatsapp informal, redes sociais não institucionais etc).

8 “o homem aprende a realidade sensível e a metaboliza em realidade inteligível” (FRANCO, 2011, p. 123).
} 
A discussão do artigo sobre processo sucessório, comunicação e cultura toma corpo na análise de variáveis como o nepotismo, paternalismo, protecionismo, comodismo, relacionamento com públicos, circulação de informação organizacional, presença (ou não) de planejamento (ROSÁRIO, 2016), pensando a sucessão como estratégia organizacional, a partir dos elementos utilizados para uma leitura comunicacional da estratégia (GOMES, 2014) sobre as decisões envolvidas nesse contexto: Identificação, Institucionalização, Mediação, Cultura Organizacional, Comunicação Organizacional (IDEM). Gomes (2014) indica um conjunto de elementos comunicacionais que possibilitam relacionar as decisões, a cultura e a comunicação organizacional. Pensar o processo sucessório familiar como "fenômeno, processo e sistema" (CURVELLO, 2009, p. 111) significa estudar o processo sucessório não apenas como uma medida de gestão administrativa, mas também como de gestão comunicacional (fenômeno). Significa estudar a produção e compartilhamento de sentidos na cultura (processo ${ }^{9}$ ) mais que apenas tarefas e papéis funcionais de indivíduos isolados. Significa entender a comunicação como definidora da construção da realidade onde interagir e comunicar é criar um universo a partir da consciência que se tem desse mundo (sistema) ${ }^{10}$.

\section{ELEMENTOS COMUNICACIONAIS DA ESTRATÉGIA NA SUCESSÃO FAMILIAR}

Gomes (2014, p. 115) identifica os elementos comunicacionais que dão suporte ao processo sucessório: a decisão, a identificação, a institucionalização, a mediação e a Cultura Organizacional. Ao se estudar o processo sucessório em empresas familiares, é possível visualizar o processo decisório do dirigente na busca por um sucessor, a identificação deste futuro sucessor em relação à organização e seus stakeholders, a institucionalização do processo no âmbito organizacional, a mediação dos conflitos e crises que poderão surgir ao longo do processo de sucessão e os efeitos dessa nova realidade na Cultura Organizacional.

A decisão está presente na organização (Sistema Social) ou nos indivíduos (Sistemas Psíqui$\cos$ ). Ela incorre na produção de sentido. E isso passa também pela comunicação interpessoal, gesticulação, linguagem corporal (uso de crachá, uniforme, adesão ao casual day). Mas, aqui, apontamos para a tomada de decisão ${ }^{11}$. Luhmann (2005) considera que as decisões são uma forma específica de comunicação. Gomes (2014, p. 116) ratifica o autor alemão e nos explica:

Nesse sentido, as decisões não são tomadas e depois comunicadas. As decisões são comunicação. Como as decisões são constituídas por duas distinções entrelaçadas, uma decisão envolve a comunicação, explícita ou implícita, de uma alternativa selecionada e de alternativas rejeitadas. Assim, a comunicação de uma decisão é paradoxal. Ela informa sobre a decisão,

9 Como processo, usando as palavras de Berlo (1972, p. 29), "não tem um começo, um fim, uma sequência fixa de eventos. Não é coisa estática, parada. É móvel. Os ingredientes do processo agem uns sobre os outros; cada um afeta todos os demais" 10 O Pensamento Sistêmico em Niklas Luhmann, fornece as bases cognitivas da construção da realidade a partir da comunicação. E a leitura comunicacional da estratégia (GOMES, 2014) nos fornece referenciais específicos para a análise organizacional dos processos sucessórios.

11 Conceito interdisciplinar que se relaciona com a Teoria da Decisão e Teoria dos Jogos. Recebe também a denominação de processo decisório. 
mas também sobre as alternativas, que, reitere-se, são e não são alternativas; caso contrário não haveria decisão. Por ser paradoxal, a comunicação da decisão é frágil e demanda uma desconstrução através de comunicações posteriores. (GOMES, 2014, p. 116).

Gomes (2014, p. 118) enfatiza a comunicação e a questão dos relacionamentos, sentimentos e comportamentos:

[...] Compreender a decisão como uma forma de comunicação pressupõe considerar a racionalidade múltipla envolvida nos comportamentos decisórios. Assim, a decisão deixa de ser um processo sequencial, linear, consciente, deliberado e planejado, em que um conjunto de alternativas é avaliado, e a melhor é feita, passando a ser compreendida como a expressão de um conjunto amplo de fatores inter-relacionados que, além da razão, envolvem afeto, intuição e relações sociais. Dessa forma, o processo decisório pode ser compreendido como não linear e transitório. (GOMES, 2014, p. 118).

Nessa perspectiva, é possível inferir que as decisões tomadas pelos gestores no cotidiano da empresa são abrangentes, profundas e holísticas. Descarta-se assim, o entendimento das decisões possuírem um cunho apenas técnico, o que nos afasta um pouco de um polo especificamente racional $^{12}$. A grandiosidade de um processo decisório se registra pela conciliação do lado técnico necessário e dos sentimentos e relacionamentos envolvidos, sejam internos ou externos à organização. Gomes (2014, p. 118) postula: "não pode haver decisões sem indivíduos e, por sua vez, organizações sem decisões". Essa característica em muito tem a ver com as lideranças e sua influência junto aos liderados e Cultura Organizacional.

A identificação é outro elemento comunicacional. Não se trata de algo eterno, definitivo, mas algo em mudança permanente. As organizações constroem e reconstroem sua identidade. Quando o indivíduo se identifica com determinada organização ou postura do predecessor e/ou sucessor, quer dizer que está convencido, convicto (pelo menos naquele momento). Entretanto, se a identificação acabar por algum motivo: é natural que a pessoa busque outro identificador. Gomes (2014, p. 120) ressalta "compreendemos a identificação como um processo de construção de identidades". Isso acontece muito no aspecto institucional, por meio de missão, visão, valores, nome (e sua mudança), lema, identidade gráfica, marca, dentre outros. No processo sucessório, certamente, abrange a questão das balizas impostas pelo sucessor e as (in)variáveis em relação ao predecessor (estilo de liderança, relacionamentos, cosmovisão, legitimidade dada pelos liderados, produção de sentido na comunicação interpessoal); além dos códigos binários, em Luhmann (2011), como familiar e não-familiar, anterior e posterior, predecessor e não-predecessor ${ }^{13}$, sucessor e não-sucessor, líder e não-líder.

\footnotetext{
12 A perspectiva de Habermas, por exemplo, é apenas racional: razão comunicativa e razão instrumental. Para Habermas, só há comunicação se houver consciência (a partir da razão) e consenso (ação comunicativa). Na perspectiva sistêmica, em Luhmann, podem ser comunicação também: a emoção e o dissenso. Nossa perspectiva em Morin: também nos afasta desta abordagem possível, em Habermas, meramente racional.

13 Predecessor e Antecessor são sinônimos. Sucessor é antônimo. Mas, em Luhmann, o código é estabelecido com o antagonismo do não como sufixo. Por isso, utilizamos predecessor e não-predecessor; e não, predecessor e sucessor, que é uma lógica a qual é mais frequente de se ter contato com esses antagonismos (a lógica de versus: predecessor versus sucessor).
} 
A institucionalização de uma empresa está diretamente ligada à cultura organizacional. Gomes (2014, p. 126) postula que "a instituição pode ser compreendida como um conjunto tanto real-social como simbólico e imaginário que se define como um universo de sentido e de ação social, como uma trama que é constantemente (re)tecida pelos sistemas sociais". Este é exatamente o polo do que é o patrimônio de sentidos da organização. E onde se criam as amálgamas dos condicionamentos sociais, tais quais linguagens, símbolos, gestos, códigos, histórias, narrativas, lendas, folclores, mitos, ritos, crenças, heróis, personagens, cerimônias, protocolos, rituais. Lembrando que a Contracultura é a força que não legitima a instituição, mera irritação. Um sucessor que não produza sentidos com efeito de confiança, legitimidade, respeito e liderança tende a ter consciências (Sistemas Psíquicos) refratárias a suas decisões para o que acredita ser o todo da organização (Sistemas Sociais). Cada adesão de consciência é um acoplamento estrutural que pode levar à formação de um Sistema Social. Um liderado pode fazer parte da estrutura funcional da organização e não concordar com a política de remuneração, por exemplo. A superação da perspectiva estrutural-funcionalista sistêmica e de outras concepções clássicas da Sociologia está em não tomar todas as pessoas com a mesma consciência apenas por estarem dispostas na mesma estrutura. Lembremos elemento anterior: as decisões não são apenas das organizações, mas também dos indivíduos. Os liderados sempre estão atentos e observando os líderes (ressonância). Assim como os sistemas, os colaboradores são vivos e buscam a manutenção de sua condição por meio da autopoiese, da autorreprodução. Em outros termos, segundo Schuler (2012, p. 255): “uma vez que a organização não se compromete com a resolução de problemas de sobrevivência das pessoas que nela atuam, estas não se comprometem com a resolução dos problemas da organização".

A mediação permite uma aproximação entre as redes de relacionamento envolvidas na resolução de conflitos ou gerenciamento de crises. Aí, sim, por meio de insumos do trabalho das carreiras de Comunicação Social, podemos pensar em termos de meios de comunicação simbolicamente generalizados, que nada mais são que a mediação da linguagem por meio da produção de estímulos (operações) que possam ser percebidos (ressonância). Essas mensagens podem circular no âmbito da organização (como entorno e ambiente) e o indivíduo estar atento a elas: observando-as (ressonância). Nessa linha, Gomes (2014, p. 129) entende que

Podemos pensar ainda nos meios de comunicação simbolicamente generalizados como unidades de sentido compartilhadas no âmbito dos sistemas sociais, que possibilitam a criação de códigos de comunicação e, com isso, fazem a mediação da comunicação responsável pela autorreprodução desses sistemas. (GOMES, 2014, p. 130).

A Cultura Organizacional pode ser considerada como o efeito difuso de interações na organização (história da organização, valores, crenças, tradição dos dirigentes, perfil dos colaboradores, estilos de liderança, gestão e de comunicação, dentre outros aspectos). A cultura existe nas organizações, mas não é definida apriorísticamente. Os colaboradores interagem nesse contexto de forma 
intuitiva, apesar de incidir sobre o cotidiano da organização. A cultura não depende de uma política institucional positivada (cartilhas, diretório no site institucional, plano de comunicação).

Curvello (2012, p. 14) afirma que a cultura organizacional ganha corpo como objeto de análise dos estudiosos de organizações:

... justamente por seu caráter de definidora das ações internas. Através da instância da cultura organizacional é possível captar a lógica das relações internas, suas contradições, suas mediações, para melhor compreender os estágios administrativos, os sucessos e fracassos organizacionais e as facilidades ou dificuldades impostas às mudanças institucionais. (CURVELLO, 2012, p. 14).

Diante de tal assertiva, é indicado que os dirigentes das empresas familiares aprimorem seus conhecimentos ou busquem no mercado profissionais/líderes qualificados para que a cultura organizacional possa ser estabelecida e praticada de maneira concreta, garantindo tanto a sobrevivência dos colaboradores quanto a continuidade da companhia no mercado.

Comunicação Organizacional é a área na qual está concentrado e alinhado este estudo. No entanto, há diversas concepções sobre este campo do saber. A integrada (KUNSCH, 2003), a qual Casali (2009, p. 34) qualifica dentro do paradigma de "Comunicação nas Organizações”: sendo os fluxos advindos das carreiras de Comunicação Social. Aqui, recuperamos um comentário de Gomes (2014), ao afirmar que:

A orientação da organização enquanto objeto defende que esta existe antes do discurso, se mantém estável ao longo do tempo e apresenta especificações de características ou componentes que moldam a utilização da linguagem. Nessa orientação, os discursos dos atores e a organização constituem níveis distintos de análise, ou seja, há uma distinção entre ação e estrutura. Geralmente, os pesquisadores envolvidos com essa orientação consideram que os discursos refletem a estrutura e procuram traçar padrões linguísticos de forma ampla, tratando os macroprocessos do discurso. (GOMES, 2014, p. 139)

E também o paradigma “Comunicação como Organizações”: onde as próprias interações dão forma à organização, o que é um foco maior, pois integra a comunicação interpessoal e na Cultura Organizacional. Este último paradigma também é tipificado como Comunicação Constitutiva, de construção e reforço de sentidos, concepção que dialoga com a perspectiva da comunicação como fenômeno, processo e sistema com a qual trabalhamos no processo sucessório.

Quadro 01 - Síntese das noções sobre Comunicação Organizacional.

\begin{tabular}{|l|l|l|}
\hline \multicolumn{3}{|c|}{ Comunicação Organizacional } \\
\hline & \multicolumn{1}{|c|}{ Comunicação “nas" Organizações } & \multicolumn{1}{c|}{ Comunicação “como" Organizações } \\
\hline Visão das Organizações & $\begin{array}{l}\text { - Unidade } \\
\text { - Máquina ou coletivo }\end{array}$ & $\begin{array}{l}\text { - Sistema de interações } \\
\text { - Construção Social }\end{array}$ \\
\hline \multirow{2}{*}{ Visão da Comunicação } & $\begin{array}{l}\text { - Variável dependente da estrutura organizacional } \\
\text { - Mecanismo para transmissão de informações e } \\
\text { manutenção da ordem organizacional }\end{array}$ & $\begin{array}{l}\text { - Elemento constitutivo das relações sociais } \\
\text { - Transação }\end{array}$ \\
\hline $\begin{array}{l}\text { Relação comunicação e } \\
\text { organização }\end{array}$ & - Conteiner & $\begin{array}{l}\text { - Produção } \\
\text { Equivalência }\end{array}$ \\
\hline Importância & $\begin{array}{l}\text { - Desempenho de funções operacionais, de ma- } \\
\text { nutenção, de relações humanas e de inovação }\end{array}$ & - Processo "organizante" \\
\hline
\end{tabular}




\begin{tabular}{|l|l|l|}
\hline & - Mensagens & \\
Foco de análise & - Canais & - Processos simbólicos de estruturação coorien- \\
& - Redes & tação e legitimação das ações sociais \\
& - Relações sociais & \\
\hline Síntese & - Clima organizacional & \\
\hline
\end{tabular}

Fonte: Casali (2006, p. 43).

Mais uma vez, um reforço da produção de sentidos. Nas palavras de Gomes (2014, p. 139-140):

Os pesquisadores que adotam a orientação da organização em permanente estado de constituição consideram que o discurso existe antes da organização e que são as propriedades da linguagem e as interações que produzem o organizing (o organizar). O enfoque está na forma como os discursos criam, mantêm e transformam os processos de organizing. Os estudos vinculados a essa orientação exploram, por exemplo, como os discursos produzem estruturas. Além de tratar os discursos como linguagem em uso, alguns estudos enfocam os Discursos (aqui propositalmente identificados com a inicial maiúscula) como sistemas gerais e duradouros para a articulação de ideias em determinados contextos. Os analistas que adotam essa orientação tendem a enfatizar a agência sobre a estrutura.

A orientação da organização alicerçada na ação procura manter um equilíbrio entre ação e estrutura, tratando ambas como mutuamente constitutivas. Essa orientação privilegia os estudos da linguagem em uso em detrimento dos estudos sobre os Discursos de poder. A organização é ancorada no nível das práticas sociais e formas discursivas, sendo considerada como um sistema social que se reproduz continuamente. O discurso, através da linguagem, importa regras e recursos organizacionais, produzindo simultaneamente a organização ao moldar processos e estruturas. (GOMES, 2014, p. 139-140)

Outra dimensão, signatária desse paradigma em processo e em construção é a perspectiva relativa ao controle da organização sobre a comunicação, em a Organização Comunicada (dimensão formal, autorizada e planejada); e a comunicação mais informal, em a Organização Comunicante (o informal com efeito sobre a produção de sentidos) e Organização falada (o informal que não interfere) (BATISTA, BALDISSERA, 2010). Como vimos, muitos são os saberes que versam sobre diversas perspectivas que dão forma às organizações ${ }^{14}$.

Quadro 02 - Os elementos comunicacionais.

\begin{tabular}{|l|l|}
\hline \multirow{2}{*}{ Decisão } & $\begin{array}{l}\text { Definição: Processo que diferencia, define e mantém os sistemas organizacionais. É fruto de uma racio- } \\
\text { nalidade múltipla, incluindo um conjunto amplo e complexo de motivações e representações da realidade } \\
\text { organizacional. A relação entre decisões constitui a estrutura que distingue os sistemas organizacionais. } \\
\text { Autores: Leitão (1997); Luhmann (2005); Miller, Hickson e Wilson (2001); Simon (1970). }\end{array}$ \\
\hline
\end{tabular}

14 A gestão de recursos e as tarefas dão forma à organização (Administração); o comportamento e o fator psíquico dão forma à organização (Psicologia); as trocas de valor, produção, distribuição de bens e serviços dão forma à organização (Economia); os parâmetros legais e jurídicos dão forma à organização (Direito); o patrimônio dá forma à organização (Ciências Contábeis); a informação processada como conhecimento dá forma à organização (Ciências da Informação); a logística e a produção dão forma à organização (Engenharia de Produção); as soluções de sistemas informacionais dão forma à organização (Tecnologia da Informação); a comunicação, interação e produção de sentido dão forma à organização (Comunicação Organizacional). 


\begin{tabular}{|c|c|}
\hline Identificação & $\begin{array}{l}\text { Definição: Processo de construção da diferença entre o sistema organizacional e o ambiente. Essa diferen- } \\
\text { ça pressupõe a definição de posições de sujeito, ou seja, de identificações. Em relação com vários sistemas } \\
\text { e em permanente tensão com o ambiente, os sistemas organizacionais são levados a construírem um con- } \\
\text { junto de identificações, que demarcam as suas fronteiras e constituem a sua identidade. A natureza comuni- } \\
\text { cacional da identificação indica a flexibilidade e a contingência da identidade dos sistemas organizacionais. } \\
\text { Autores: Baldissera (2007); Gershon (2005); Hall (2009); Iasbeck (2009); Luhmann (2011); Silva (2009); } \\
\text { Vizer (2011); Woodward (2009). }\end{array}$ \\
\hline Institucionalização & $\begin{array}{l}\text { Definição: Processo em que grupos sociais são criados e perpetuados, em uma lógica de dominação ou po- } \\
\text { der compartilhado, que envolve a busca por legitimação de práticas, decisões e estruturas. Revela o poder } \\
\text { de convocação de um universo autorreferenciado de sentidos, que leva as organizações a (re)produzirem } \\
\text { suas próprias estruturas e as estruturas dos sistemas com os quais se relacionam. } \\
\text { Autores: DiMaggio e Powell (2005); Hasse (2005); Luhmann (2005; 2011); Meyer e Rowan (1977); } \\
\text { Tolbert e Zucker (1998); Vizer (2011). }\end{array}$ \\
\hline Mediação & $\begin{array}{l}\text { Definição: Envolve as construções culturais e simbólicas, as apropriações e recodificações das mensagens/ } \\
\text { discursos, que são responsáveis pela criação de sentidos. A mediação ocorre através das práticas cotidianas, das } \\
\text { técnicas incorporadas nos processos organizacionais, dos rituais e da circulação de sentidos nas organizações. } \\
\text { Autores: Luhmann (2011); Martin-Barbero (2006); Signates (2003); Verón (1980). }\end{array}$ \\
\hline $\begin{array}{l}\text { Cultura } \\
\text { Organizacional }\end{array}$ & $\begin{array}{l}\text { Definição: Uma construção simbólica de sentidos compartilhados na organização. Pode ser considerada } \\
\text { uma premissa decisória ou condição produtiva para as decisões estratégicas. Envolve um processo cole- } \\
\text { tivo de construção e de compartilhamento das formas de ver, interpretar e compreender a realidade, que } \\
\text { pode condicionar e deixar marcas nas decisões. } \\
\text { Autores: Enriquez (1997); Gherson (2005); Hardy e Clegg (2001); Motta e Vasconcellos (2008); Schein } \\
\text { (2007); Scroferneker (2010). }\end{array}$ \\
\hline $\begin{array}{l}\text { Comunicação } \\
\text { Organizacional }\end{array}$ & $\begin{array}{l}\text { Definição: Na perspectiva sistêmico-discursiva, a comunicação pode ser considerada a essência da orga- } \\
\text { nização. Através dela é construída e mantida a distinção entre sistema e ambiente. Ela envolve tanto os } \\
\text { processos formais, autorizados e planejados, quanto os processos informais, deflagrados nas relações dos } \\
\text { sistemas organizacionais com outros sistemas do seu ambiente. É constituída na circulação, multiplicação } \\
\text { e disputa de sentidos, incluindo desvios, dissensos e indeterminações. } \\
\text { Autores: Baldissera (2008, 2009); Curvello (2009); Deetz (2001); Fairhurst e Putman (2010); Fausto Neto } \\
\text { (2008); Luhmann (2006; 2011); Marshack e Grant (2008); Restreppo (1995); Verón (1996). }\end{array}$ \\
\hline
\end{tabular}

Fonte: (GOMES, 2014, p. 146) com adaptações.

\section{EMPRESAS FAMILIARES - DAS DEFINIÇÕES A OPERAÇÕES SISTÊMICAS}

O conceito de empresa familiar não é pacífico, mas é moldado por características como o fato de atuarem no agronegócio, comércio e serviços (JUNIOR, 2011, p. 23), a ideia de perpetuação do negócio em prol da próxima geração (GALLO, 1995, p.32), o fato de ter tempo médio de vida das empresas familiares é de 24 anos, com apenas 5\% delas sobrevivendo além da terceira geração (DAVIS et al,1997, p. 11), a concentração em um só produto e ramo de atividade (IDEM), a falta de planejamento estruturado e conflitos em razão da sucessão (IDEM), o padrão de comportamento baseado na emoção e poderosamente influenciado no subconsciente (LEACH, 1994, p. 47), empresas familiares locais, regionais nacionais e multinacionais (CASILLAS, 2007, p. 11), de propriedade e forma jurídica em responsabilidade limitada, sociedade anônimas, capital aberto (IDEM).

Nos estudos, geralmente, são classificadas por: primeira geração (direção de fundadores: controle dos processos organizacionais e detendo o poder decisório); segunda geração (filhos e sobrinhos de fundadores à frente da gestão: podendo caracterizar toda a filiação ou somente um ou alguns); 
e terceira geração (netos de fundadores: com tendência ao estabelecimento de sistemas formais de relações entre a companhia e a família) (CASILLAS, 2007, p. 52). São classificações da autora:

a) A "empresa de trabalho" familiar: é aquela cujos membros da família pretendem gerenciá-la, com a maior parte deles atuando na empresa, se assim o desejarem. Desse modo, incentiva-se que os filhos trabalhem na empresa do pai e assim por diante, geração após geração, porém respeitando-se a vontade desses descendentes;

b) A "empresa de direção" (administração) familiar: trata-se da empresa em que os membros da família concordam em manter o controle apenas sobre a propriedade, transferindo a direção e a gestão da empresa aos familiares que tenham mais habilidade e formação. Nesse caso, portanto, somente alguns dos familiares têm realmente direito de trabalhar na empresa e de nela ocuparem cargos de responsabilidade. Os demais membros permanecem vinculados à empresa como cotistas/acionistas;

c) A "empresa familiar de investimento": os membros da família proprietária dedicam-se exclusivamente a controlar as decisões de investimento e desinvestimento em diferentes negócios, e não na gestão da empresa. O objetivo é manter maior liberdade de atuação, sem comprometer uma vinculação excessivamente estreita da família com determinado negócio da empresa. Procura-se maximizar a rentabilidade que os membros da família possam obter por meio dos negócios que realizam;

d) A "empresa familiar conjuntural": é aquela empresa em que não existe claro interesse da família em futuramente manter a propriedade ou a gestão sobre ela. $\mathrm{O}$ vínculo existente é resultado de circunstâncias históricas (herança de negócios ou patrimônios). No futuro, esse tipo de empresa tende a se desfazer assim que houver uma oferta de investidores externos (CASILLAS, 2007, p.14).

Nos tipos descritos, verificam-se importantes características quanto a finalidades (onde, certamente, incorre a estratégia, missão, visão, valores e o próprio cumprimento dos objetivos organizacionais). Na alínea "a", ressalta-se o empenho na continuidade da organização, mantendo as futuras gerações no comando. Assim, é possível que os herdeiros sustentem-se dos lucros oriundos da empresa. Na alínea "b”, há uma preocupação, mesmo que incipiente, em profissionalizar a gestão: quando os familiares mais habilidosos são designados aos cargos de responsabilidade. Os demais continuam ligados à empresa por força de lei. A alínea “c”, os familiares são mantidos nas decisões referentes aos investimentos (conselhos de administração e votantes), uma vez que, os demais setores da empresa são delegados a profissionais habilitados para tal. Na alínea "d", observa-se uma situação bastante peculiar, pois não há interesse em continuidade da empresa no mercado: o que oportuniza oferta de compra por investidores em aquisições e incorporações.

Como fatores negativos nas empresas familiares, a atuação dos familiares converge para sobreposição de papéis quanto à atividade profissional e particular. Seus integrantes conduzem as ações na empresa como se estivessem tomando decisões familiares. Assim, os valores interpessoais tornam-se predominantes no processo decisório organizacional, relevando para segundo plano: a gestão profissional. Como elemento garantidor deste comportamento está a propriedade ${ }^{15}$. O salvo conduto do

15 A própria ideia de propriedade privada é baseada na família e no direito de herança. 
clã quanto à gestão empresarial revela-se pela certeza de seu patrimônio. Enquanto proprietários, a preocupação de dar continuidade à companhia é uma questão secundária ${ }^{16}$ à autoridade e ao controle.

O nepotismo é facilmente encontrado em empresas familiares.

O paternalismo é uma realidade negativa encontrada em empresas familiares não profissionalizadas. O dirigente concentra todo o poder em suas mãos, não delegando e não confiando em seus subordinados, sejam eles parentes (ou não). Assim, o primeiro estatuto de poder é a liderança. Com um líder paternalista e detentor de total poder, em situações peculiares (como por exemplo: uma viagem de férias) as decisões são definidas somente após o seu retorno.

O protecionismo na empresa familiar diz respeito a privilegiar determinado membro da família, sem considerar sua capacidade para desempenhar a função designada. Caso o profissional cometa erros na função, o detentor do poder o minimiza suas falhas ou o deixa impune.

O comodismo caracteriza-se pela falta de comprometimento do clã na gestão, em razão do vínculo familiar e da certeza de auferir vantagens sem a preocupação de envolvimento direto no exercício da administração. Fator que se relaciona com a falta de interesse em profissionalizar a gestão.

A falta de limite entre o privado e organizacional com a retirada de numerário para suprir gastos pessoais considerados supérfluos. Os rendimentos são destinados a suprir a necessidade pessoal individual, não havendo preocupação quanto às questões de garantia econômica da própria empresa ${ }^{17}$.

Ausência de planejamento empresarial de médio e longo prazo, incluindo, a dificuldade em selecionar e capacitar os sucessores. O desafio está nos sentidos, valores, cultura, normas e princípios que possam ser compartilhados no âmbito da empresa entre sucessores e organização, a fim de garantir a coesão, o alinhamento e a manutenção da relação entre empresa e família.

É certo que os fatores negativos apresentados não ocorrem em todas as empresas familiares. Alguns predominam em detrimento de outros. Donnelley (1976, p. 55) afirma que isso acontece quando a família não soube integrar senso de responsabilidade e de respeito à companhia. E isso pode ser pensado como Comunicação.

Fatores positivos nas empresas familiares que possibilitam crescimento pleno, reconhecimento, continuidade e estabilidade no mercado são apontados Leite (2011, p. 31) com os mais comuns:

[...] é o orgulho pela empresa, isto é, a atitude de vestir a camisa, de não ter horário para sair, de levar o trabalho para casa, de dispor dos fins de semana para convivência com pessoas do trabalho. Destacam-se entre outros aspectos fundamentais ao êxito de empresas familiares: disponibilidade de recursos financeiros e administrativos impossíveis de se obter de outra forma, devido a sacrifícios feitos pela família; importantes relações comunitárias e comerciais

16 [...] como fatores negativos nas empresas familiares, destacam-se: paternalismo, protecionismo, conflitos familiares que se refletem no dia a dia organizacional, ausência de disciplina e de comprometimento empresarial, comodismo dos familiares, falta de interesse em profissionalizar a gestão, retirar, sem preocupação futura, numerário para suprir gastos pessoais considerados supérfluos, promoção de parentes que não possuem as qualificações adequadas, ausência de planejamento empresarial de médio e longo prazos, incluindo, a dificuldade em selecionar e capacitar os sucessores (LODI, 1998, p. 41).

17 Maquiavel (1989, p. 168) já registrava com sabedoria "que o príncipe que se baseia inteiramente na fortuna vai à ruína assim que ela varia”. 
decorrentes de um nome respeitado; sensibilidade pelas responsabilidades sociais; o nome da família pode ter grande reputação no estado, na região ou no país inteiro, funcionando como uma cobertura econômica e política; um sistema de decisão rápido (LEITE, 2011, p. 31).

Nome e renome fazem parte disso. De acordo com Leite (2011, p. 31), dedicação, disciplina, profissionalização e responsabilidade são fatores influenciadores do convívio social. O nome da família se consagra na exata proporção de sua responsabilidade em desenvolver e dar garantia de renda às famílias. Por conseguinte, sua reputação e imagem no mercado tornam-se fortalecidos, dando o caráter de continuidade da empresa.

A produção de sentido pode tomar forma na adesão ("vestir a camisa"), clima (sem pressa em encerrar expediente), relacionamento (sem aborrecimentos). Um diferencial em relação a gestões profissionalizadas é a ideia de que todos, patrões e empregados, dependem dos objetivos organizacionais para a subsistência e manutenção de vida: como um projeto coletivo, de comunidade.

A amálgama do tecido social, que se relaciona com a Cultura Organizacional, é a confiança. Uma competência e um sentido compartilhado pelos liderados: classificados como formas de integridade (honestidade: a garantia de lisura nas relações como um sentido), competência (habilidade e perícia: a garantia do cumprimento de tarefas e do compromisso com outras pessoas e etapas), consistência (autoconfiança: a garantia de que há um norte força para superar obstáculos), lealdade (proteção e defesa dos mais fracos: a garantia que alguém assina e reponde por quem tem menos poder) e abertura (a confiança plena: a garantia de que os relacionamentos, contratos sociais e verbais não serão rompidos) (RODRIGUES, 2010, p. 55).

A troca de informações como processo comunicacional. Preconiza de forma objetiva a interação entre os colaboradores e clientes de acordo com suas pretensões e necessidades, visando atender as expectativas de ambas as partes. Curvello (2012, p. 25-26) afirma que a Comunicação Organizacional, entretanto, está inserida no macro ambiente que exerce forte influência, agindo por meio de fatores psicológicos, sociais e culturais e que muitas vezes interfere decisivamente no processo comunicativo.

\section{O PROCESSO SUCESSÓRIO EM EMPRESAS FAMILIARES COMO COMUNICAÇÃO}

A interpretação desta seção é com base no clã familiar como referência, pois o processo sucessório da troca de liderança entre predecessor e sucessor é o foco. No entanto, as mesmas interpretações podem ser feitas com base nos liderados, levando em conta a produção de uma leitura comunicacional (GOMES, 2014), conforme seção anterior.

O clã pode ser entendido como um Sistema Social operacionalmente fechado, que observa outros sistemas no sentido de fazer sua manutenção e existência. A ideia de perpetuação do negócio em prol da próxima geração (GALLO, 1995, p.32) passa pela autopoiese e a manutenção do sistema, que é de código binário: familiar e não-familiar. O planejamento pode ser entendido como programação: um rol de operações, ou seja, de decisões (comunicações). Mesmo sabendo-se que a falta 
de planejamento e conflitos decorrentes desse processo (DAVIS et al,1997, p. 11), além de fatores imponderáveis das organizações marcadas por contextos da Complexidade, incidem sobre a sucessão. Neste sentido, também percebemos o Paradoxo de Decisão: decidir é escolher perante o desconhecido. Decidir é escolher uma realidade (certeza), dentre tantas que podem existir (incerteza).

A programação é feita nas organizações com as decisões, que viram regras a serem reificadas na Cultura Organizacional (redundância: repetição) e criam modelos de procedimentos, de conduta, valores, crenças. Em outras palavras, promove a institucionalização, elemento da nossa leitura comunicacional (GOMES, 2014).

As interações afetam todas as comunicações com Sistemas Psíquicos (pessoas) e Sistemas Sociais (pessoas e pessoas). As classificações dos tipos de empresas familiares e das gerações sucessórias - primeira geração; segunda geração; e terceira geração (CASILLAS, 2007, p. 52) - mostram que mesmo pertencendo a um sistema, cada familiar tem sua consciência, cosmovisão e interação na organização: “empresa de trabalho" (direção família), "empresa de direção” (administração como cotistas e acionistas), "empresa familiar de investimento" (decisões de investimento e desinvestimento e não na gestão: conselheiros) e "empresa familiar conjuntural” (vínculo apenas pela herança e patrimônio) (CASILLAS, 2007, p.14). Cada sistema tem consciência e está posicionado, ora como observador; ora, como observado. Estamos sempre observando e sendo observados: Alter e Ego. É a base do efeito cognitivo que forma a Cultura Organizacional, elemento da nossa leitura comunicacional (GOMES, 2014).

O sistema é operacionalmente fechado e está isolado, mas observa os outros sistemas e interage, ora na produção de sentido quando interage com o entorno ou ambiente (acoplamento estrutural), ora na coordenação desses sentidos com outros sistemas (interpenetração).

A falta de planejamento formal incide também sobre o padrão de comportamento baseado na emoção e poderosamente influenciado no subconsciente (LEACH, 1994, p. 47), uma marca das empresas familiares que enfatiza mais ainda a personificação da liderança. A decisão organiza a realidade complexa (improbabilidade da comunicação). As empresas familiares são organizadas por decisões: do predecessor e do sucessor. Mudou a administração, tudo em decorrência pode mudar.

A sociedade é organizada por decisões, elementos centrais da nossa leitura comunicacional (GOMES, 2014). As organizações, igualmente. O salvo conduto do clã mostra um subsistema familiar dentro da organização familiar: em que a impunidade, (in)justiça social e a (in)justiça corporativa podem ser operações, contingências, estímulos, irritações. Há outros sentidos e formas de comunicação que podem ser compartilhados no ambiente organizacional como seleção de marcas negativas do processo sucessório na empresa familiar: o nepotismo, o paternalismo, o protecionismo, o comodismo.

O nome e renome da família são sentidos identitarios que são compartilhados (ou não) pelas lideranças e liderados no processo sucessório, incorrendo nos sentidos de adesão ("vestir a camisa"), percepção do clima, relacionamentos, Integridade, competência, consistência, lealdade. Como visto, a identificação é um elemento da nossa leitura comunicacional (GOMES, 2014). 


\section{CONSIDERAÇÕES FINAIS}

O processo sucessório em empresa familiar não está circunscrito apenas à liderança do predecessor e do sucessor. Aspectos como estratégia, planejamento, finanças, legalidade, aspectos técnicos, administrativos, comerciais e patrimoniais se relacionam com comunicação e cultura em sentidos produzidos e compartilhados na organização. Da mesma forma, relacionam-se com relações de confiança, poder, sentimentos de pertença ao grupo, tradição, afetuosidade, animosidade e subjetividades. O pensamento sistêmico, em Luhmann (2011), nos ajuda a trazer a comunicação para o centro deste contexto marcado pela complexidade, além de permitir trabalhar com questões como o dissenso sendo também uma forma de comunicação que evidencia os conflitos inerentes à sucessão. Em meio à globalização e às diversas formas de aquisições e incorporações de companhias, muitas empresas familiares passam por processos de reestruturação que mexem com dinâmicas norteadoras de sua base cognitiva, como a Cognição Social e a Cultura Organizacional. Nesse sentido, utilizando a alegoria de Luhmann (2011), ocorrem diversos ruídos, irritações, seleção, acoplamento estrutural e ressonâncias que influenciam as consciências individuais (Sistemas Psíquicos) e os arranjos ou grupos sociais (Sistemas Sociais) levando à preservação da organização (autopoiese) ou mesmo ao seu fim (encerramento operativo do sistema).

Uma limitação deste trabalho está no fato de ser teórico e não ter uma base empírica com a qual possa trabalhar autonomamente (objetivo, inclusive, de outras aplicações). Além do fato de, ao interpretar e tentar ver o processo sucessório nas empresas familiares como um processo comunicacional organizacional, poder desconstruir pressupostos e premissas de saberes que produziram a maioria dos estudos sobre o tema. O estudo de Rosário (2016) é a primeira aplicação sobre a questão no campo da Comunicação. No entanto, na Administração, já há um arcabouço teórico avançado sobre o assunto baseado em pressupostos como o da empresa (em vez de organização); de boa gestão (pois, na Administração, o objetivo daquele saber é produzir entendimento para a melhor gerência de recursos, ou seja, perseguir objetivos de sucesso, eficiência, eficácia e efetividade, tendo como base a racionalidade econômica). Entretanto, em Comunicação, primeiramente, estamos preocupados com a caracterização das interações e da produção de sentido, mais do que com a (in)gerência, (in)eficiência, (in)eficácia e (in)sucesso, além de prescrições do tipo.

Nossa abordagem, inédita e pioneira na área, contudo, reconhece que não há, ainda, no campo da Comunicação Organizacional, subsídios e aplicações suficientes para evoluir o tema de exploratório para confirmatório. Reconhece-se que são poucas as inserções de estudos em Comunicação sobre processo sucessório familiar ${ }^{18}$. Por enquanto, ainda estamos no plano interpretativo. E essa é uma oportunidade do trabalho: tentar traduzir e transportar para a Comunicação as múltiplas possibilidades de um tema visto como tradicionalmente vinculado ao campo da Administração e/ou do Direito.

18 Vide trabalho da Universidade de Montreal sobre o assunto: Le processus de succession dans les entreprises familiales: une perspective discursive (GUIMOND, 2011). 


\section{REFERÊNCIAS}

BATISTA, D. C. ; BALDISSERA, Rudimar. Entre a organizações comunicada e a falada: a comunicação organizacional da empresa Tramontina C. B. S/A. Iniciacom: revista brasileira de iniciacao cientifica em comunicacao social, v. 2, p. 01-21, 2010.

BERTALANFFY, Ludwig von. Teoria Geral dos Sistemas. Rio de Janeiro: Vozes, 1977.

CASILLAS, José Carlos et al. Gestão da empresa familiar. Conceitos, casos e soluções. São Paulo: Thomson, 2007.

CARTONI, Daniela. Apostila Consultoria Empresarial Profa Daniela Maria Cartoni. Grupo Ibmec Educacional, Metrocamp - Grupo Ibmec. 2011

CASALI, Adriana. Comunicação organizacional em fusões e aquisições internacionais. (Tese, Doutorado em Engenharia de Produção e Sistemas). UFSC. 2006. 203 f.

CURVELlO, João José Azevedo. A Comunicação Organizacional como fenômeno, como processo e como sistema. Organicom. Ano 6. Edição especial, números 10/11, 2009.

CURVELlO, João José Azevedo. Comunicação interna e cultura organizacional. Brasília: Casa das Musas, 2012.

CURVELlo, João José Azevedo; SCROFERNEKER, Cleusa. A comunicação e as organizações como sistemas complexos: uma análise a partir das perspectivas de Niklas Luhmann e Edgar Morin. E-Compós, Brasília, v. 11, p. 1-16, 2008.

DAVIS, John \& al. Generation to generation - life cycles of the family business. Harvard Business School Press, USA, 1997.

FRANCO, Lucio Flavio. Comunicação, cognição e acaso nas organizações: uma pesquisa sobre os novos modelos empresariais na economia digitalizada. Tese de doutorado. PUC- SP, 2011.

GOMES, Victor Márcio Laus Reis. Uma leitura comunicacional da estratégia na perspectiva sistêmico-discursiva. Tese de doutorado da Faculdade de Comunicação Social. PUC, Porto Alegre, 2014. 
GUIMOND, Jonathan. Le processus de succession dans les entreprises familiales: une perspective discursive. (Dissertation, maîtrise en communication). Université de Montréal. 2011

JUNIOR, Armando Lourenzo Moreira. Bastidores da empresa familiar. Como reduzir conflitos por meio da governança corporativa. São Paulo: Atlas, 2011.

MARCONDES FILHO, C. J. R.. De repente, o prédio falou comigo. Anotações sobre experiências metapóricas em Teoria da Comunicação. In: 20o. Encontro Anual da Compós, 2011, Porto Alegre. Anais do 20o. Encontro Anual da Compós. Porto Alegre: UFRGS e Fabico, 2011.

LEACH, P. Family business. London: Stoy Hayward, 1994.

LEITE, Gleucir. Processo de sucessão e desafios da profissionalização: estudo em quatro empresas familiares na região metropolitana de Belo Horizonte/MG. Dissertação de Mestrado em Administração. Faculdade Novos Horizontes, Belo Horizonte, MG, 2011.

LUHMANN, Niklas. The paradox of decision making. In: SEIDL, David. BECKER, Kai H. (Org.). Niklas Luhmann and Organization Studies. Copenhagen: Copenhagen Business School Press, 2005.

LUHMANN, Niklas. A realidade dos meios de comunicação. São Paulo: Editora Paulus, 2011.

MACHADO, Fabíola de Araújo. A Comunicação Organizacional e a rede de decisão nas organizações: um estudo sobre a Caixa e a nova classe média. Dissertação do PPGSSCOM/UCB, Brasília, UCB, 2015.

MATURANA, Humberto R. e VARELA, Francisco J. A árvore do conhecimento: as bases biológicas da compreensão humana. São Paulo: Palas Athena, 2011.

RODRIGUES, Léo Peixoto \& NEVES, Fabrício Monteiro. Niklas Luhmann: A sociedade como sistema. Porto Alegre: EdiPUCRS, 2012.

ROSARIO, Ivone Maria Correia de Almeida do. Processo sucessório em empresas familiares: uma leitura a partir da comunicação organizacional e suas dimensões. (Dissertação, Mestrado em Comunicação) UCB. 2016.

SILVA, Jaqueline Claudino da. Sustentabilidade em contexto organizacional: análise de modelos de gestão à luz da perspectiva sistêmica de Niklas Luhmann. Dissertação. Mestrado em Gestão e Sustentabilidade. Universidade Estadual de Londrina (PR), 2015. 